\title{
The association between gang involvement and sexual behaviours among detained adolescent males
}

\author{
D R Voisin, L F Salazar, R Crosby, R J DiClemente, W L Yarber, M Staples-Horne
}

Sex Transm Infect 2004;80:440-442. doi: 10.1136/sti.2004.010926

Objective: Data were collected from 270 detained male adolescents (aged 14-18 years) to determine the association between ever having been in a gang and a range of sexual behaviours such as sexual activity, male condom use, sex with multiple partners, and drug use during sex.

Methods: Participants answered survey questions using audio computer assisted self interviewing (A-CASI) procedures, which assessed demographic, family factors, history of gang membership, and sexual behaviours.

Results: Multiple logistic regression analyses, controlling for demographic, socioeconomic status, and family factors, indicated that adolescents who reported having been in a gang, relative to their peers reporting no gang involvement, were 5.7 times more likely to have had sex, 3.2 times more likely to have got a girl pregnant, and almost four times more likely to have been "high" on alcohol or other drugs during sexual intercourse, have had sex with a partner who was "high" on alcohol or other drugs, or have had sex with multiple partners concurrently.

Conclusions: Findings suggest that having been in a gang can discriminate between levels of STI associated risk behaviours among an otherwise high risk populationdetained adolescent males.

D etained adolescent males, relative to all other adolescent populations, report substantially higher rates of sexual activity, inconsistent or no condom use, a greater number of multiple sexual partners, and drug use during sex. ${ }^{1}$ Consequently, this population is at higher risk for becoming infected with sexually transmitted infections (STIs). ${ }^{2}$

The literature is replete with diverse theories as to what causes risk behaviours among adolescents. Among them, control theory ${ }^{3}$ posits that adolescent risk behaviours are to a certain extent caused by weak bonds to conventional society represented in part by limited parental attachment. ${ }^{4}$ In contrast, social learning theory ${ }^{5}$ asserts that affiliation with negative peer groups can be a strong and consistent predictor of risky behaviours. ${ }^{6}$ This study examined whether ever having been a gang member would be independently associated with sexual risk behaviours among detained adolescent males, after controlling for perceived family social support, socioeconomic status, and demographic variables.

\section{METHODS}

Administrators from eight detention facilities located in Georgia were solicited for their cooperation in a cross sectional survey of male adolescent detainees. Between October 2001 and July 2003, research assistants screened adolescents to determine eligibility for study participation. Adolescents were eligible if they were male, 14-18 years old, expressed willingness to participate, and provided written participant assent and verbal parental consent. The institutional review boards at Emory University and the State Juvenile Justice Department approved all study procedures. All self reported measures were assessed using audio computer assisted self interviewing (A-CASI) which has been shown to reduce problems related to reporting bias, recall, and illiteracy. ${ }^{7}$

\section{Measures}

Gang involvement, the predictor variable was determined by asking adolescents whether they were ever a gang member.

Covariates assessed were age, ethnicity, medication for mood/behaviour disorders, family's receipt of public assistance, and perceived family social support. ${ }^{8}$

\section{Outcomes}

Sexual behaviours assessed whether adolescents ever had vaginal or oral sex; used male condoms the last time they had sex; had ever got a girl pregnant; had currently got a girl pregnant; in the last 2 months before being detained wanted to have sex but did not have a condom available; had sex with multiple partners concurrently; had sex while high on alcohol or drugs; and had sex with a partner who was high on alcohol or drugs.

\section{Data analysis}

Univariate analyses were used to describe the overall sample. Prevalence ratios, their 95\% confidence intervals, and the corresponding $\mathrm{p}$ values were calculated. ${ }^{9}$ We conducted separate logistic regressions to examine the relation between having ever been in a gang and the occurrence of each risk outcome, adjusting for covariates which were selected based on empirical or theoretical considerations. ${ }^{10}$ All analyses were performed using SPSS (version 12.0).

\section{RESULTS}

The study enrolled 270 male adolescents. Of the total sample, $40.7 \%$ identified as white and non-Hispanic and $39.6 \%$ as African-American. Descriptive statistics of the sample are described in table 1. Of the total sample, $84.3 \%$ reported having had sex. Among these youth, 37.2\% reported not using a male condom during last sex, 24\% reported ever getting a girl pregnant, and $11.2 \%$ had currently got a girl pregnant. Over the past 2 months before being detained, $32.4 \%$ had sex with multiple partners concurrently, 58\% were high on alcohol or drugs during sex, and $44 \%$ had a partner high on alcohol or drugs during sex.

Logistic regression analyses illustrated that after controlling for potentially confounding covariates, ever having been in a gang was associated with a greater prevalence of sexual risk behaviours. Adolescents who had a history of gang

Abbreviations: A-CASI, audio computer assisted self interviewing; STIs, sexually transmitted infections 


\begin{tabular}{|lcc|}
\hline \multicolumn{3}{|c|}{ Table $1 \quad$ Demographic characteristics of the sample } \\
\hline Characteristic & Number & $\%$ \\
\hline Age (years) & 133 & 49.5 \\
$14-15$ & 132 & 49.0 \\
$16-17$ & 4 & 1.5 \\
18 & 109 & 40.7 \\
Race & 107 & 39.9 \\
White & 34 & 12.7 \\
Black & 18 & 6.7 \\
Hispanic & 75 & 28.0 \\
Other & & \\
Medication to control mood/ & \\
behaviours & 6 & 2.2 \\
Living arrangements & 72 & 26.9 \\
With girlfriend or alone & 131 & 48.9 \\
Both parents & 8.2 \\
Mother only & 22 & 13.8 \\
$\quad$ Father only & 37 & 3.3 \\
Other relative or other & 9 & 33.9 \\
TANF recipient in the present & & \\
household & & \\
History of gang membership & 82 & \\
\hline TANF, temporary assistance for needy families. & \\
\hline
\end{tabular}

membership compared to peers with no gang involvement were 5.7 times more likely to have had sex. Among sexually active males, those who were ever involved in a gang, compared to their counterparts, were 3.2 times more likely to have got a girl pregnant in the last 2 months before being detained, 3.4 times more likely more likely to have had an incident of wanting to have sex and not have a condom available; 3.4 times more likely to have had sex with multiple partners concurrently; 3.4 times to get high on alcohol or drugs during sex; and 3.3 times more likely to have sex with a partner who was high on alcohol or other drugs (table 2). Notably, in all logistic models, perceived family social support was a significant correlate only for condom availability $(p=0.004)$. For every 1 unit increase of perceived family social support, adolescents were more likely to report approximately $15 \%$ increase in condom availability.

\section{DISCUSSION}

This study indicates that a history of gang membership is associated with a spectrum of STI risk behaviours. While any one of the risk behaviours identified would be a cause for concern, it is the pattern of findings across cognate domains that are particularly significant. The consistency of observed associations, even after controlling for potential confounding influences, suggests that among this already high risk adolescent subgroup, adolescents with a history of gang membership are at markedly higher risk for behaviours that place them at increased vulnerability for STIs including HIV. Although evidence from previous research suggests that gang membership may be an important indicator of sexual risk among female adolescents, ${ }^{11}$ this study's findings add to the empirical literature by characterising the effect of gang membership on an understudied high risk populationdetained male adolescents.

The cross sectional research design does not allow us to determine whether the relation between gang involvement and sexual health behaviours was causal. In addition, it is possible that risk takers may be more inclined to join a gang, or be recruited by gangs, than are adolescents who are risk adverse. Findings are limited by the validity of the self reported measures and response bias (although A-CASI technology was employed) and the use of a convenience sample. Although we assess for mood and behavioural disorders, taking medicine prescribed by a doctor may be a poor proxy for mental health status given the inadequacy of the availability of mental health services for youth. Future research would need to examine contextual factors related with gang involvement, such as length of gang involvement, the perceived social norms of the gangs, or the type of gangs in which participants were involved (that is, drug or street gangs).

Given the weight of findings suggesting that gang membership may be a cauldron for adolescent males' acquisition of risky sexual practices, STI intervention studies of these adolescent males are warranted. Preventing gang involvement is an important prevention strategy for detained youth. Other strategies to consider would be helping youths who are already in gangs to get out of them, and promoting greater parental supervision and involvement in their adolescents' lives. In addition, providing behavioural change intervention to adolescent male gang members using ex-gang members as peer educators in treatment facilities may prove to be an efficacious method for reducing their STI risk, and by extension the risk of their sex partners. Intervention methods that include screening and treating adolescent male gang members for STIs may also prove successful. ${ }^{12}$ Given the strong possibility that previously detained adolescent males

Table 2 Unadjusted and adjusted analyses measuring the association between gang involvement and sexual behaviours among detained adolescent males, Georgia, 2001-3

\begin{tabular}{|c|c|c|c|c|c|c|c|}
\hline \multirow[b]{3}{*}{ Behaviours } & \multicolumn{7}{|c|}{ Bivariate analyses } \\
\hline & \multicolumn{5}{|c|}{ Gang membership } & \multicolumn{2}{|c|}{ Multivariable analyses } \\
\hline & Yes & No & $\mathrm{PR}^{*}$ & $95 \% \mathrm{Cl} \dagger$ & p Value & OR $\ddagger(95 \% \mathrm{Cl})$ & p Value \\
\hline \multicolumn{8}{|l|}{ Sexual activity } \\
\hline $\begin{array}{l}\text { Had sex } \\
\text { Condoms }\end{array}$ & 95 & 77 & 1.2 & 1.1 to 1.4 & 0.001 & 5.7 (1.8 to 17.3$)$ & 0.002 \\
\hline No male condom last sex & 45 & 34 & 1.3 & 0.9 to 1.9 & 0.13 & $1.0(0.5$ to 1.9$)$ & 0.09 \\
\hline \multicolumn{8}{|l|}{ Pregnancy } \\
\hline Ever got a girl pregnant & 39 & 15 & 2.5 & 1.5 to 4.0 & 0.001 & $3.2(1.5$ to 6.6$)$ & 0.002 \\
\hline $\begin{array}{l}\text { Current pregnancy } \\
\text { Sexual }\end{array}$ & 18 & 07 & 2.8 & 1.3 to 6.1 & 0.01 & $2.6(1.0$ to 7.2$)$ & 0.06 \\
\hline Had multiple partners§ & 46 & 21 & 2.2 & 1.4 to 3.3 & 0.001 & $3.4(1.8$ to 6.6$)$ & 0.000 \\
\hline Sex while high on drugs§ & 73 & 46 & 1.6 & 1.2 to 2.0 & 0.001 & $3.4(1.7$ to 6.4$)$ & 0.000 \\
\hline Sex while partner high on drugs§ & 58 & 35 & 1.7 & 1.2 to 2.3 & 0.002 & $3.3(1.7$ to 6.4$)$ & 0.000 \\
\hline
\end{tabular}

*PR, prevalence ratio; adolescents having no history of gang involvement was the referent for computing the PR. $\uparrow 95 \% \mathrm{Cl}, 95 \%$ confidence interval.

†OR, odds ratio adjusted for age, ethnicity, behaviour medication, receipt of TANF, and perceived family social support.

§ln the 2 months before being admitted to the detention centre. 
who belong to a gang may be core transmitters, intervention specifically targeting this group could substantially reduce STI incidence within the affected sexual networks.

\section{ACKNOWLEDGEMENTS}

This research was supported, in part, by the Emory Center for AIDS Research (NIH/NIAID 2 P30 AI50409-04Al), the Rural Center for AIDS/STD Prevention at Indiana University, and a grant from the University Research Council at Emory University.

\section{CONTRIBUTIONS}

DV, LS, and RD contributed to the design, analysis and interpretation of the data; RD, LS, RC, WY, and MS-H contributed to the conception and acquisition of that data; all authors provided intellectual content for this manuscript.

\section{Authors' affiliations}

D R Voisin, University of Chicago, School of School of Social Service

Administration, Chicago, IL, USA

L F Salazar, R J DiClemente, Rollins School of Public Health, Department of Behavioral Sciences and Health Education, GA, USA

R Crosby, R J DiClemente, Emory Center for AIDS Research, GA, USA

R Crosby, R J DiClemente, W L Yarber, Rural Center for AIDS/STD Prevention at Indiana University, IN, USA

R Crosby, R J DiClemente, Kentucky School of Public Health, KY, USA R J DiClemente, Emory University School of Medicine, Department of Pediatrics, GA, USA

W L Yarber, Kinsey Institute for Research in Sex, Gender, and Reproduction, Indiana University, IN, USA

W L Yarber, Department of Applied Health Science at Indiana University, IN, USA

M Staples-Horne, Georgia Department of Juvenile Justice, GA, USA
Correspondence to: Dexter R Voisin, School of Social Service Administration, University of Chicago, 969 East 60th Street, Chicago, IL 60637, USA; d-voisin@uchicago.edu

Accepted for publication 23 August 2004

\section{REFERENCES}

1 Magura S, Shapiro L, Kang S. Condom use among criminally-involved adolescents. AIDS Care 1994;6:595-603.

2 Vermund SH, Alexander-Rodriguez T, MacLeod S, et al. History of sexual abuse in incarcerated adolescents with gonorrhea or syphilis. J Adolesc Health Care 1990;11:449-52.

3 Hirschi T. Causes of delinquency. Berkeley: University of California Press, 1969.

4 Glueck S, Glueck E. Unraveling juvenile delinquency. New York: Commonwealth Fund, 1950

5 Bandura A. Perceived self-efficacy in the exercise of control over AIDS infection. Paper presented at the National Institutes of Mental Health and Drug Abuse Research Conference on Women and AIDS: Promoting Health Behaviors. Bethesda, MD, 1987.

6 Cohen AK. Delinquent boys. Glencoe, IL: Free Press, 1995.

7 Turner CF, Ku L, Rogers SM, et al. Adolescent sexual behavior, drug use, and violence: increased reporting with computer survey technology. Science 1998;280:867-71.

8 Zimet GD, Dahlem NW, Zimet SG, et al. The Multidimensional Scale of Perceived Social Support. J Pers Assess 1988;52:30-41.

9 Hosmer D, Lemeshow S. Applied logistic regression. New York: John Wiley \& Sons, 1989.

10 Resnick M, Bearman P, Blum R, et al. Protecting adolescents from harm: findings from the national longitudinal study on adolescent health. JAMA 1997;278:823-32.

11 Wingood GM, DiClemente RJ, Crosby RA. Gang involvement and the health of African-American female adolescents. Pediatrics 2002;110:57-62

12 Deschenes EP, Esbensen F. Violence in gangs: gender differences in percepton of behavior. J Quant Criminol 1999;15:63-96. 